\title{
TUGAS TEORI KOMUNIKASI
}

Tugas Individu Membuat Review Dari Jurnal Penelitian

Dalam Bentuk Makalah ( Paper )

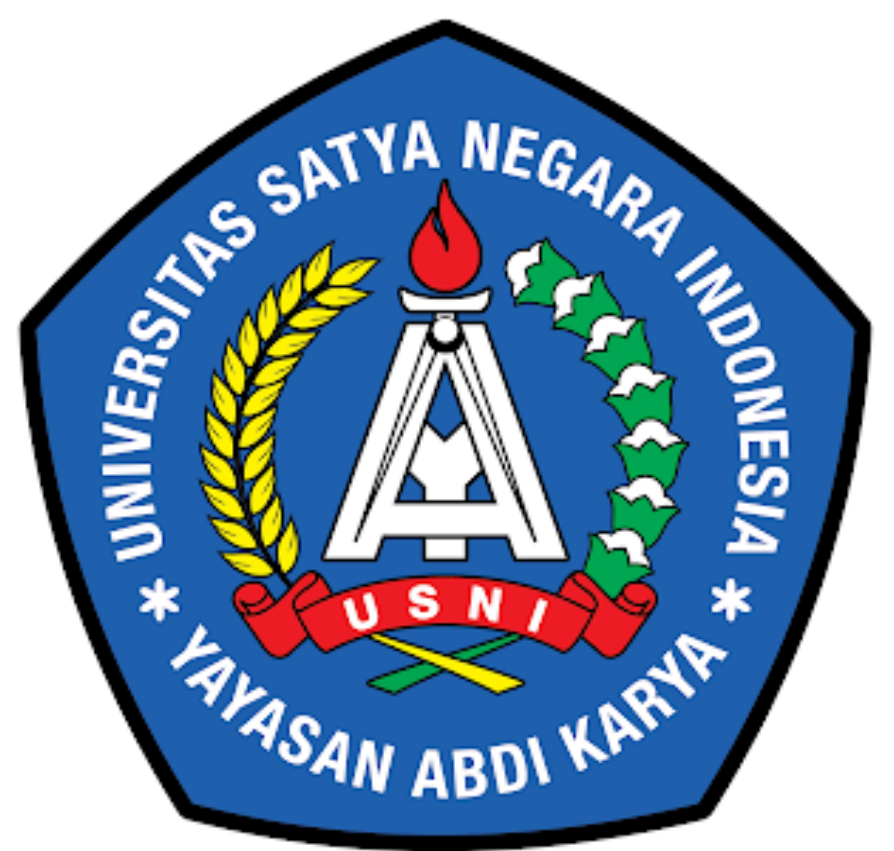

Di susun oleh : Astri Ananda ( 180900100 )

Mata kuliah : Teori Komunikasi

Nama dosen : Radita Gora Tayibnapis, S.Sos, M.M.

\author{
FAKULTAS FISIP \\ JURUSAN ILMU KOMUNIKASI \\ UNIVERSITAS SATYA NEGARA INDONESIA
}




\section{Tugas Individu Membuat Review Dari Jurnal Penelitian Dalam Bentuk Makalah ( Paper )}

\section{Soal :}

1. Tugas individu ( Perorangan ) membuat review dari Jurnal Penelitian dalam bentuk Makalah ( Paper ) yang di ambil dari Google Scholar. Kata kunci ( Search ) : Radita Gora.

2. Silahkan memilih salah satu judul Penelitian di Jurnal Penelitian berikut :

a. Modernity In Hedonic Life Youth Women ( Structure Of Sosialite Groups Among College Students In Jakarta ).

b. Social Capital Of Entrusted Service Agents For Imported Fashion And Cosmetics Products.

c. Demokrasi Deliberatif Politik Pekerja Pers.

d. Komodifikasi Model Endorse Dalam Industri Budaya Fashion Dan Kosmetika ( Hiperrealitas Fashion Endorse Pada Produk Kosmetik Dan Busana Remaja Di Media Sosial Instagram ).

e. Perspektif Feminis Dalam Media Komunikasi Film ( Wacana Kritis Perjuangan Keadilan Gender Dalam Film “ Three Billboard Outside ).

3. Pada review Jurnal Sebutkan dan jelaskan teori-teori yang di gunakan pada penelitian dari Jurnal Penelitian tersebut. Jelaskan pengertian dan asumsi dari teori tersebut dan berikan contoh kasus lain berdasarkan teori tersebut.

4. Review paper bisa di kutip dari buku-buku berikut :

a. TEORI KOMUNIKASI ( Human Pf Communication Theories ). Stephen W. Little John \& Karen A. Foss, Edisi 9 ( 2009 ).

b. Ensiklopedia Teori Komunikasi (Encyclopedia Of Communication Theories ). Stephen W. Little John \& Karen A. Foss, Edisi 9 ( 2009 ).

c. Pengantar Teori Komunikasi ( Analisis Dan Aplikasi ). Shane West \& Lynn H. Turner ( 2009 ).

d. Handbook Of Teori Sosial. Barry Smart ( 2010 ).

5. Review dalam bentuk Paper minimal 10 halaman. Ukuran kertas A4, jenis font Times New Roman, Font. ( Ukuran 12 PT ). Di kumpulkan dalam bentuk PDF. 
6. Tugas di kumpulkan maksimal pada pertemuan ke-7 dalam bentuk Soft Copy. Tugas di upload melalui osf.io ( Silahkan bikin akun dulu di WWW.osf.io ) dan di upload melalui estudy.id.

7. Pada akhir makalah review wajib mencantumkan Bibliography ( Daftar Pustaka). Pengutipan sumber harus melalui Software MENDELEY. ( Tidak di perkenankan untuk pengutipan secara manual ).

8. Larangan keras mengutip dari Internet, Blog, dan sebagainya. Wajib mengutip dari buku.

9. Boleh di dukung pengutipan dari buku Teori Komunikasi lain. ( Hanya sebagai pendukung ) namun tetap harus ada mengutip dari buku utama yang ada di dalam list. 


\section{DAFTAR ISI}

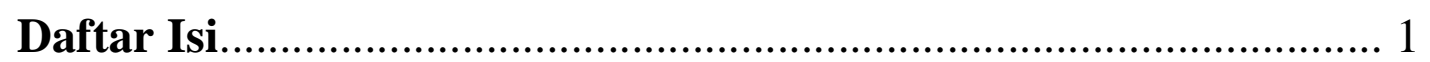

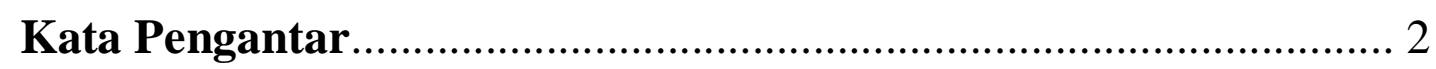

\section{BAB I PENDAHULUAN}

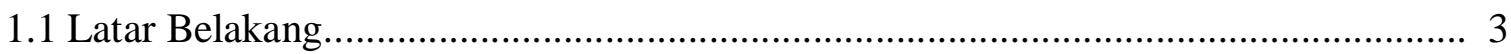

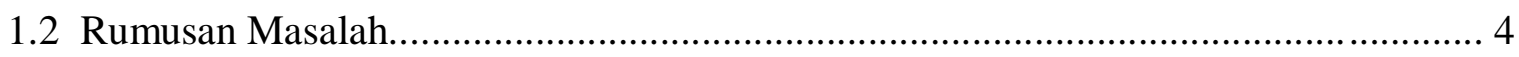

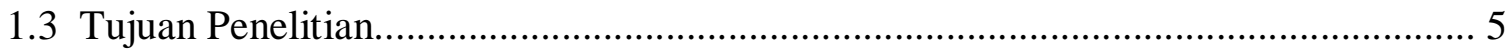

\section{BAB II PEMBAHASAN}

2.1 Pentingnya Media Sosial ( Digital ) Dalam Industri Budaya Fashion

Dan Kosmetika 6

2.2 Penjelasan Tentang Komodifikasi Model Endorse Dalam Industri Budaya Fashion Dan Kosmetika..................................................................................... 7

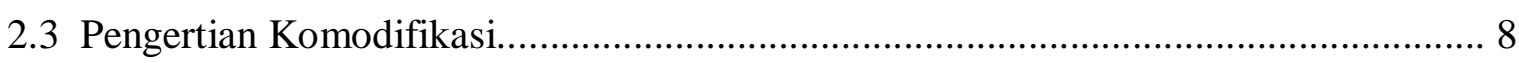

2.4 Contoh Dari Komodifikasi Model Endorse Dalam Industri Budaya Fashion

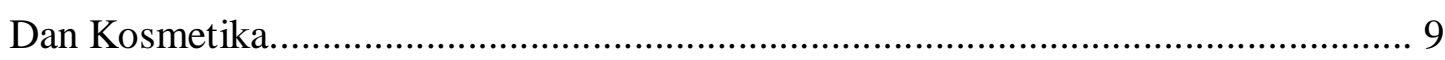

2.5 Penjelasan Mengenai Metode Penelitian Yang Di Gunakan Dalam Penelitian Tersebut. .10

\section{BAB III PENUTUP}

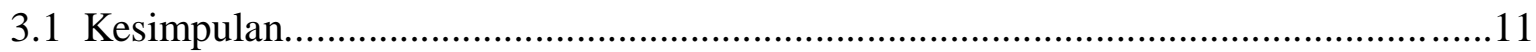

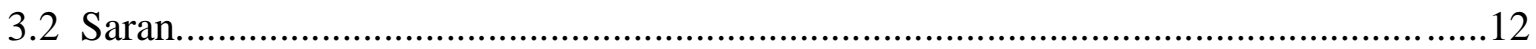

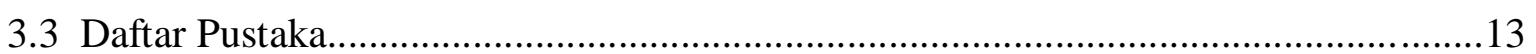




\section{KATA PENGANTAR}

Puji Syukur kehadirat Allah SWT yang telah memberikan rahmat dan hidayah-Nya sehingga saya dapat menyelesaikan tugas mereview sebuah Jurnal menjadi sebuah makalah yang berjudul " Komodifikasi Model Endorse Dalam Industri Budaya Fashion Dan Kosmetika ( Hiperrealitas Fashion Endorse Pada Produk Kosmetik Dan Busana Remaja Di Media Sosial Instagram ).”

Ada pun tujuan dari penulisan dari makalah ini adalah untuk memenuhi tugas Pak Radita Gora Tayibnapis, S.Sos, M.M. pada pelajaran Teori Komunikasi. Selain itu, makalah ini juga bertujuan untuk menambah wawasan tentang Komodifikasi Model Endorse Dalam Industri Budaya Fashion Dan Kosmetika untuk saya sendiri dan pembaca yang lainnya.

Saya mengucapkan terima kasih kepada Pak Radita Gora Tayibnapis, S.Sos, M.M. selaku Dosen dari Pelajaran Teori Komunikasi yang telah memberikan tugas ini sehingga dapat menambah pengetahuan dan wawasan sesuai dengan bidang studi yang saya tekuni.

Jakarta, 6 Oktober 2020

Astri Ananda 


\section{BAB I \\ PENDAHULUAN}

\subsection{Latar Belakang}

Komodifikasi itu ialah suatu proses yang erat untuk di kaitkan dengan kapitalisme yang di mana objek-objek, kualitas-kualitas, dan tanda-tanda di ubah menjadi komoditas. Komoditas sendiri pun di pahami sebagai sebuah barang yang tujuan utama keberadaannya adalah untuk di jual di pasar. Pada studi media pun, kajian komoditas sering di manfaatkan untuk beragam riset yang mencakup objek iklan ( seperti objek orang tua, ana-anak, laki-laki, dan perempuan pada suatu iklan ), kemudian objek orang pada suatu tayangan televisi untuk menaikkan rating sebuah tayangan film, kemudian komoditas konten pada pemberitaan seperti kasus pelecehan atau kekerasan pada perempuan dan anak kemudian konten politik dan lain sebagainya.

\subsection{Rumusan Masalah}

1. Bagaimana media sosial ( Digital) di gunakan dan di kembangkan dalam Komodifikasi Model Endorse Dalam Industri Budaya Fashion Dan Kosmetika?

2. Jelaskan tentang Komodifikasi Model Endorse Dalam Industri Budaya Fashion Dan Kosmetika !

3. Apa yang di maksud dengan komodifikasi ?

4. Sebutkan contoh dari Komodifikasi Model Endorse Dalam Industri Budaya Fashion Dan Kosmetika !

5. Apa saja metode penelitian yang di gunakan untuk membahas penelitian tersebut dan jelaskan?

\subsection{Tujuan Penelitian}

Agar dapat menyelesaikan tugas mereview sebuah Jurnal menjadi sebuah makalah yang berjudul “ Komodifikasi Model Endorse Dalam Industri Budaya Fashion Dan Kosmetika ( Hiperrealitas Fashion Endorse Pada Produk Kosmetik Dan Busana Remaja Di Media Sosial Instagram ).” Dan dapat menambah pengetahuan dan wawasan sesuai dengan bidang studi yang saya tekuni. 


\section{BAB II \\ PEMBAHASAN}

\subsection{Pentingnya Media Sosial ( Digital ) Dalam Industri Budaya Fashion Dan KosmetikaMengenai Metode Penelitian Yang Di Gunakan Dalam Penelitian Tersebut}

Media sosial sebagai bagian dari budaya populer bukan hanya di gunakan oleh khalayak luas untuk menampilkan suatu identitas diri melalui perwajahan di internet, melainkan juga di manfaatkan sebagai sarana berbisnis global. Seperti halnya produk fashion di media instagram sebagai sarana promosinya, termasuk menjadikan publik amatir sebagai model endorse untuk produk fashion dan kosmetika. Namun kegandrungan para remaja menjadi modelini kemudian terlihat sebagai bentuk pemanfaatan tubuh sebagai “ Alat Jual " untuk mempromosikan produk dan meningkatkan nilai jual produk yang di promosikan. Sehingga dalam penelitian ini memfokuskan pada persoalan komodifikasi remaja sebagai model endorse di media sosial instagram yang menjadi salah satu media sosial populer di masyarakat. Teori yang di gunakan dalam penelitian ini menggunakan Teori Simulacra menurut perspektif Baudrillad dalam kebudayaan modern. Pendekatan riset dalam penelitian ini adalah dengan metode Semiotika. Hasil penelitian menunjukkan bahwa pemaknaan terhadap tanda pada iklan produk, penggunaan model yang tidak di kenal bagi pihak produsen di untungkan dengan model amatir yang memiliki perawakan yang mumpuni serta di bayar murah dan bisa mendatangkan keuntungan agar mampu memikat pelanggannya untuk mencoba memakai produk yang di tawarkan dan berusaha untuk mneyerupai. Sehingga aspek infrastruktur ini sebagai bagian kekuatan kapitalis dalam mendatangkan keuntungannya serta bentuk ideologis penanaman kesadaran palsu tentang prestise individu.

Industri fashion dan kosmetika hingga saat ini masih merajai item-item produk yang di tawarkan di dalam e-commerce. Vendor-vendor baru terus bermunculan di situs jual-beli produk mengingat aktivitas atau kegiatan secara online lantaran internet adalah ladang bisnis baru bagi pebisnis muda atau pebisnis pemula. Sebagian besar pelaku transaksi e-commerce melalui toko online masih mendominasi transaksi bisnis fashion. Sebagian besar reesponden mengakui bahwa berbelanja produk fashion melalui e-commerce lebih mudah. Hal ini terungkap dalam survei bisnis e-commerce yang di lakukan Idea atau Asosiasi E-commerce Indonesia. Dalam survei ini sekitar 78 persen responden mengakui berbelanja fashion mealui 
e-commerce. Angka ini di atas transaksi barang lainnya seperti ponsel yang mencapai 46 persen dan benda-benda elektronik lainnya yang mencapai 43 persen dari total responden.

Cara berbelanja melalui online juga mengubah kebiasaan masyarakat Indonesia dalam berbelanja. Perkembangan internet mengubah cara pandang seseorang dalam membeli barang. Selain itu, para responden mengatakan bahwa belanja melalui toko online di anggap lebih mudah. Ramainya pengguna e-commerce di Indonesia membuat nilai transaksinya terus bertambah.

Fashion dan kosmetika, bagi masyarakat modern tidak lagi di anggap sebagai pemenuhan kebutuhan sekunder, namun juga di pandang sebagai kebutuhan primer yang harus terpenuhi. Sehingga penawaran tren busana-busana baru dengan beragam variasi atau model-model yang beragam dan dari berbagai versi, memudahkan bagi para konsumen atau khalayak luas dalam memilih produk meskipun penawaran produk dan jenis busana atau kosmetik yang di tawarkan memiliki banyak jenis dan beragam. Sehingga keberadaan fashion dan produk kosmetik yang di taawarkan terus menjadi incaran bagi para khalayak luas terutama yang tersegment pada remaja di tingkat pendidikan Menengah dan pendidikan tinggi. Upaya memenangkan persaingan bisnis tersebut, maka produsen baju pun berlombalomba untuk membuat media promosi dengan desain iklan yang menarik di media digital, eye catching serta menggunakan model-model yang memiliki perawakan dari wajah atau badan yang sesuai dengan penangkapan kamera atau di kenal dengan istilah camera face dan memiliki perawakan yang menjual. Sehingga dengan begitu dapat mendukung produk agar mudah terjual dengan terus mendengungkan brand ( merek ) produk di media komunikasi massa digital karena ada ketertarikan konsumen atau calon konsumen terhadap model ataupun produk yang di jual.

\subsection{Penjelasan Tentang Komodifikasi Model Endorse Dalam Industri Budaya Fashion Dan Kosmetika}

Endorse sendiri sebenernya bukan praktik baru dalam aktivitas marketing. Apabila mengacu pada vendor-vendor lama atau yang sudah menjadi pebisnis lama di bidang fashion dan kosmetika, biasanya paradigma konvensional yang di gunakan adalah dengan berpromosi memanfaatkan model terkenal atau selebritis terkenal. Sebagian besar pelaku usaha fashion melalui e-commerce meyakini bahwa penggunaan endorse mampu mendongkrak penjualan produk busana, di satu sisi para pelaku usaha pun kadang tidak canggung untuk memberikan 
kompensasi rendah kepada pihak model endorse agar dapat memperoleh keuntungan yang besar dari produk yang di jual.

Adapun keberadaan bahwa yang di kenakan oleh model endorse juga bertujuan untuk di tiru oleh khalayak luas dan membuat masyarakat meniru style busana yang di kenakan oleh model yaang di mana visualisasi promosi produk tersalurkan melalui media sosial. Sehingga upaya promosi melalui media sosial pun di kemas dan di bangun sekreatif pada konten pesannya agar bisa semenarik mungkin di media sosial seperti halnya media sosial visual instagram dan mampu membentuk kesadaran palsu bagi khalayak, sehingga tersimulasi dengan memercayai output pola fashion dan kosmetik yang sesuai dengan konten promosi dan kualitas hasil yang bersifat fiksi.

\subsection{Pengertian Komodifikasi}

Komodifikasi itu ialah suatu proses yang erat untuk di kaitkan dengan kapitalisme yang di mana objek-objek, kualitas-kualitas, dan tanda-tanda di ubah menjadi komoditas. Komoditas sendiri pun di pahami sebagai sebuah barang yang tujuan utama keberadaannya adalah untuk di jual di pasar. Pada studi media pun, kajian komoditas sering di manfaatkan untuk beragam riset yang mencakup objek iklan ( seperti objek orang tua, ana-anak, laki-laki, dan perempuan pada suatu iklan ), kemudian objek orang pada suatu tayangan televisi untuk menaikkan rating sebuah tayangan film, kemudian komoditas konten pada pemberitaan seperti kasus pelecehan atau kekerasan pada perempuan dan anak kemudian konten politik dan lain sebagainya.

\subsection{Contoh Dari Komodifikasi Model Endorse Dalam Industri Budaya Fashion Dan Kosmetika}

Seperti pada iklan seorang perempuan sedang menempelkan spon bedak di pipinya, terdapat nilai-niali yang ingin di komunikasikan atau di promosikan melalui apa yang ditampilkan. Iklan ini menampilkan kehidupan sehari-hari perempuan berhijab dengan menggunakan riasan wajah yang terlihat natural, selain itu juga di tampilkan perempuan yang sedang memakai bedak dengan wajah yang berseri-seri. Sudah jelas bahwa perempuan berhijab dalam iklan ini hanya di jadikan sebagai alat komodifikasi untuk menarik minat pembeli. Iklan sendiri tidak menyadari bahwa iklan yang mereka produksi mengandung nilai komodifikasi. Meskipun sebenarnya wujud dari komoditas tersebut hanyalah pendefinisian manusia yang mengambil wujud fantastis dari suatu hubungan di antara benda-benda hasil 
produksi. Itulah mengapa dalam iklan ini kosmetik Sophie Paris, menggunakan perempuan berhijab yang menjadi sebuah bahan yang menarik untuk di tampilkandan di komodifikasikan.

Dapat di jelaskan bahwa terdapat komodifikasi pada iklan ini. Dimana iklan ini mengkomodifikasikan mengenai wanita hijab sebagai identitas seorang muslimah.bukti dari komodifikasi wanita hijab ini dapat di ejlaskan dengan visual yang ada dan di perkuat dialog, bahwa menggunakan hijab merupakan identitas seorang muslimah. Penggunaan hijab dapat di gunakan untuk membedakan wanita apakah Muslim atau Non Muslim. Fungsi hijab bukan hanya untuk menutup kepala tetapi dapat di simpulkan sebagai identitas seorang Muslimah. Komodifikasi Muslimah modern dalam iklan ini dapat di tunjukkan dengan riasan wajah yang di tampilkan dalam setiap shotnya oleh model cantik tersebut.

Iklan Sophie Paris di gambarkan dengan menampilkan nilai keagamaan untuk kepentingan pengiklan. Nilai-nilai keagamaan dalam iklan ini yang seharusnya bersifat sakral mengalami rekonstruksi makna. Di mana yang awalnya berhubungan dengan ketuhanan sekarang di alih fungsikan sebagai media periklanan yang secara jelas bersifat komersil. Dalam iklan ini perempuan berhijab di produksi menjadi komoditas untuk di perjual belikan melalui media periklanan yang yang seolah-olah layak untuk di konsumsi masyarakat.

Proses komodifikasi yang muncul pada iklan Sophie Paris adalah komodifikasi konten yang dapat di lihat dari tanda-tanda dan gambaran cerita iklan tersebut. Sophie Paris mencoba menjual psannya terhadap masyarakat luas melalui iklan televisi dan menggunakan tema islami. Unsur nilai agama dalam iklan terasa sangat kuat ketika dalam iklan tersebut memunculkan visualisasi yang menyerupai dengan kenyataan kehidupan masyarakat. Dari sinilah terlihat jelas bahwa pengiklan menyiapkan materi konstruksi realitas di mana media massa berpihak kepada pemilik modal atau kapitalis. Hal ini di lakukan untuk mendapatkan keuntungan yang berlimpah sesuai yang di harapkan pengiklan.

\subsection{Penjelasan Mengenai Metode Penelitian Yang Di Gunakan Dalam Penelitian Tersebut Paradigma Penelitian}

Metode penelitian yang di gunakan dalam penelitian ini adalah dengan menggunakan penelitian kualitatif melalui analisis teks media iklan promosi di media sosial dengan memaknai tanda dan simbol pada media.

Paradigma penelitian yang di gunakan dalam penelitian ini menggunakan paradigam kritis. Paradigma ini ingin mengoreksi pandangan konstruktivisme yang kuran sensitive pada 
proses produksi dan reproduksi makna yang terjadi secara historis maupun institusional. Paradigam kritis, sebagai suatu tradisi intelektual dengan seperangkat keyakinan dalam melihat sebuah fenomena permasalahan secara kritis dengan membedah ideologi, dan sebagai bentuk pencerahan ( enlightment ) produsen melalui teks maupun konteks produk di dalam pemuatannya pada media iklan promosi di media sosial.

\section{Pendekatan Riset ( Metode Semiotika )}

Pendekatan riset dalam penelitian ini menggunakan dengan metode semiotika. Sederhananya, semiotika ( semiotics ) merupakan studi tentang tanda-tanda. Tanda adalah bagian dari kehidupan sosial, mereka bermakna untuk sesuatu yang lain. Semiotika menunjukkan bahwa apa yang kita anggap sebagai " alami " dan " jelas " dalam wacana publik perlu di pertimbangkan dalam konteks. Artinya, nilai-nilai kita dan struktur keyakinan yang sering merupakan akibat dari apa yang telah di wariskandari generasi ke generasi ( tradisi ). Semiotika menantang gagasan bahwa kata-kata memiliki makna yang sesuai, memang, kata-kata berubah maknanya seiring dengan orang yang menggunakan kata-kata tersebut juga berubah.

Semiotika atau penyelidikan simbol-simbol, membentuk tradisi pemikiran yang penting dalam teori komunikasi. Metode semiotika terdiri atas sekumpulan metode tentang bagaimana tanda-tanda mempresentasikan benda, ide, keadaan, situasi, perasaan, dan kondisi di luar tanda-tanda di luar itu sendiri. Penyelidikan tanda-tanda tidak hanya memberikan cara untuk melihat komunikasi, melainkan memiliki pengaruh yang kuat pada hampir sama perspektif yang sekarang di terapkan pada teori komunikasi.

Semiotika selalu di bagi ke dalam tiga wilayah kajian semantik, sintatik, dan pragmatik. Semantik berbicara tentang bagaimana tanda-tanda berhubungan dengan yang di tunjuknya atau apa yang di tunjukkan oleh tanda-tanda. Wilayah kajian kedua dalam semiotika adalah sintaktik atau kajian hubungan di antara tanda-tanda. Oleh karena itu, sintaktik mengacu pada aturan-aturan yang dengannya orang mengkombinasikan tanda-tanda ke dalam sistem makna yang kompleks. Pragmatik, kajian utama semiotika yang ketiga, memperlihatkan bagaimana tanda-tanda membuat perbedaan dalam kehidupan manusia atau penggunaan praktis serta berbagai akibat dan pengaruh tanda pada kehidupan sosial. Paling tidak, boleh di katakan bahwa ketiga dimensi semiotika ini berkaitan satu sma lainnya dan bahwa pemisahannya membantu dalam memahami aspek makna yang berbeda. 


\section{Teori Simulacra}

Zaman kode telah menggantikan zaman tanda. Hubungan antara kode dengan reproduksi-reproduksi yang asli. Pada " kode " mensyaratkan bahwa objek yang di hasilkan sebagaimana jaringan pada bologi bukan seperti salinan sebagaimana bisa di pahami, di mana salinan sebagai reproduksi dari objek yang asli. Perbedaan antara salinan dengan yang asli justru menjadi berlebihan. Realitas semu ( virtual reality ) komunikasi global, hologram, dan seni adalah wilayah yang menunjukkan bentuk simulacra.

Konsep simulacra bagi Jena Baudrillard pada masyarakat modern, kenyataan telah di gantikan dengan simulasi kenyataan, yang hanya di wakili oleh simbol dan tanda. Siapa membangun persepsi paling kuat adalah ia pemenang. Persepsi ini, meskipun bukan kenyataan sebenarnya telah di yakini sebagai kebenaran mutlak. Pada saat itulah terjadi yang di percayai sebagai sumber kebenaran bukan relaitas.

Jean Baudrillard menyebutkan pada bagian simulacra adalah mulai masa Renesains sampai awal revolusi Industri. Dalam skema era ini yang dominan adalah counterfeit ( pemalsuan yang asli ), pemalsuan pada tahapan ini masih alami, di mana tanda-tanda masih merefleksikan realitas yang mendasarinya. Pemalsuan di sini kemungkinan tidak dapat memberikan kontrol atas masyarakat yang berada dalam simulacra. Hal biasanya dapat di temukan dalam imajinasi dan gambar, dalam tiruan dan imitasi yang bersifat harmonis, optimis, dan bertujuan mengembalikan yang hilang.

Simulacra telah di jadikan cara untuk pemenuhan kebutuhan masyrakat konsumen atas tanda. Dan sebagai masyarakat yang terbanjiri oleh citra dan informasi yang ada, maka simulasi telah membuat citra menjadi suatu hal yang paling di minati dan di perhatikan dalam kebudayaan masyarakat pasca modern. Kemudian dasri sinilah kenyataan di produksi oleh simulasi berdasarkan model-model ( yang tidak memiliki asal-usul atau referensi realitas ) dan secara artificial di reproduksi sebagai kenyataan.

Simulacra merupakan pemikiran yang di tawarkan Jena Baudrillard tentang media massa yang di cirikan oleh realitas semu ( hyperrealitas ) dan simulasi ( simulation ). Konsep ini mengcau pada suatu realitas baik virtual ataupun artifisial dalam komunikasi massa dan konsumsi massa. Realitas tersebut membentuk manusia dalam berbagai bentuk simulasi. Simulasi merupakan suatu realitas yang pada dasarnya bukan realitas sesungguhnya. Ia hanya realitas yang di bentuk oleh kesadaran manusia melalui media massa.

Pesan-pesan media terpenuhi oleh gambar-gambar simbolis yang memang di rancang untuk memengaruhi individu dan masyarakat. Oleh karena itu, gagasan Baudrillard benar- 
benar menyebrangi tradisi semiotika dan tradisi kritis, dan keprihatinan akan keadaan masyarakat kontemporer mengantisipasi tradisi sosiokultural juga.

\section{BAB III \\ PENUTUP}

\subsection{Kesimpulan}

Dari penelitian yang sudah di lakukan maka dapat di tarik kesimpulan bahwa hijab yang seharusnya di gunakan sebagai ibadah untuk memenuhi perintah Allah bagi kaum Muslimah untuk menutup suratnya, tetapi dalam kenyataannya hijab terjadi perubahan di mana nilai barang menjadi nilai tukar yang bersifat komersil yang terdapat dalam iklan kosmetik Sophie Paris.

Komodifikasi yang muncul pada iklan Sophie Paris adalah Komodifikasi isi atau konten yang terlihat dari cerita dan tanda-tanda yang di tampilkan pada iklan tersebut. Di sini iklan Sophie Paris mencoba menjual pesan yang mereka sampaikan kepada khalayak melalui iklan yang di tayangkan pada televisi yang menggunakan tema Perempuan Berhijab. Hijab dalam iklan ini memiliki unsur yang sangat kuat ketika dalam iklan tersebut memunculkan visualisasi yang menyerupai dengan realitas kehidupan masyarakat. Dari sinilah terlihat jelas pengiklan menyiapkan materi konstruksi realitas dengan keberpihakan media massa kepada pemilik modal atau kapitalis. Hal ini di lakukan untuk mendapatkan keuntungan yang besar sesuai yang di harapkan pengiklan.

Komodifikasi yang terjadi dalam iklan ini di awali dengan memasukkan konsep Perempuan berhijab ke dalam iklan. Dari iklan tersebut di hasilkan penggunaan hijab yang telah di komodifikasikan dalam iklan Sophie Paris “ Natural \& Halal “. Iklan tersebut mengalami peregeseran dengan nilai fungsi ke nilai tukar. Di mana nilai fungsi hijab yang seharusnya di pergunakan untuk beribadah kepada Allah, namun dalam kenyataannya di jadikan sebagai pengeruk keuntungan yang berlimpah untuk sebuah perusahaan. 


\subsection{Saran}

Saya tentunya masih menyadari jika makalah di atas masih terdapat banyak kesalahan dan jauh dari kesempurnaan. Jika banyak kesalahan dalam penulisan saya memohon maaf kurang lebihnya. Saya akan memperbaiki makalah tersebut dengan berpedoman pada banyak sumberr serta kritik yang membangun dari para pembaca.

\subsection{Daftar Pustaka}

(Gora and Olifia)Gora, Radi, and Sandra Olifia. "Komodifikasi Model Endorse Dalam Industri Budaya Fashion Dan Kosmetika.” Ilmu Komunikasi, 2018, p. 14.

Littlejohn, Stephen W., and Karen A. Foss. Teori Komunikasi. Edited by Ria Oktafiani, Salemba Humanika, 2014.

West, Richard, and Lynn H. Tumer. Pengantar Teori Komunikasi Analisis Dan Aplikasi. Edited by Aklia Suslia and Didik Erma Irawan, 5th ed., Salemba Humanika, 2017.

(Littlejohn and Foss)Gora, Radi, and Sandra Olifia. "Komodifikasi Model Endorse Dalam Industri Budaya Fashion Dan Kosmetika.” Ilmu Komunikasi, 2018, p. 14.

Littlejohn, Stephen W., and Karen A. Foss. Teori Komunikasi. Edited by Ria Oktafiani, Salemba Humanika, 2014.

West, Richard, and Lynn H. Tumer. Pengantar Teori Komunikasi Analisis Dan Aplikasi. Edited by Aklia Suslia and Didik Erma Irawan, 5th ed., Salemba Humanika, 2017.

(West and Tumer)Gora, Radi, and Sandra Olifia. "Komodifikasi Model Endorse Dalam Industri Budaya Fashion Dan Kosmetika.” Ilmu Komunikasi, 2018, p. 14.

Littlejohn, Stephen W., and Karen A. Foss. Teori Komunikasi. Edited by Ria Oktafiani, Salemba Humanika, 2014.

West, Richard, and Lynn H. Tumer. Pengantar Teori Komunikasi Analisis Dan Aplikasi. Edited by Aklia Suslia and Didik Erma Irawan, 5th ed., Salemba Humanika, 2017. 